\title{
Contemporary Applications For Spatially Integrated Social Science
}

\author{
Jonathan Corcoran ${ }^{1} \cdot$ Nik Lomax $^{2} \cdot$ John Lombard ${ }^{3}$ \\ Accepted: 9 August 2021 / Published online: 16 August 2021 \\ (C) The Author(s), under exclusive licence to Springer Nature B.V. 2021
}

\section{Introduction}

The spatialization of the social sciences is a movement that continues to gain momentum. From its early origins in the late 1990s (Anselin, 1999; Goodchild, et al., 2000) to its more contemporary applications (Stimson, 2014) the integration of space and place and assessment of their evolution over time through the use of GIS-based techniques and technologies now spans both quantitative and qualitative approaches (Goodchild \& Janelle, 2004). Nationally funded research centres that include The Center for Spatially Integrated Social Science (CSISS) in the United States and the Australian Research Council Network in Spatially Integrated Social Science (ARCRNSISS) in Australia go some way to highlight the interest in and importance of viewing social science questions through a spatial lens.

By emphasising the role and importance of space and place (and their evolution over time), spatially integrated social science seeks to better understand the complex social processes that govern contemporary society. In other words, by situating a given topic of interest within a spatial (and temporal) framework we are better able to inform decision making targeted at addressing the challenges facing people and places. Furthermore, the appreciation of the power that a spatially orientated approach to the social sciences can offer has in turn fuelled a growing diversity of studies that together have developed new theory, tools, techniques and data sets that promote the integration of space into the social sciences.

Jonathan Corcoran

jj.corcoran@uq.edu.au

Nik Lomax

n.m.lomax@leeds.ac.uk

John Lombard

jlombard@odu.edu

1 Queensland Centre for Population Research, The University of Queensland, Brisbane 4072, Australia

2 School of Geography, University of Leeds, Leeds LS2 9JT, UK

3 School of Public Service, Old Dominion University, Norfolk, VA 23529, USA 
The aim of this special issue is to bring together recent scholarship that serve to highlight the breadth of research undertaken at the interface of the social and spatial sciences. Each of these papers, led by researchers from a broad range of disciplines, are drawn from recent meetings of the Applied Geography Commission (2021), a Commission of the International Geography Union that was re-established in 2000 under the leadership of Antiones Bailly (Phlipponneau, 2004). Our hope is that this carefully curated set of papers offer Applied Spatial Analysis and Policy readers a set of studies which showcase the latest international research on the use of spatial analytic approaches to understanding contemporary social challenges.

\section{Special Issue Papers}

The first paper by Gordon Mulligan examines how the pattern of patents issued for 377 urban areas across the United States have changed over a 25-year period. Using regression accounting for spatial effects the paper highlights the increasingly important role played by both human capital and amenities in shaping the changing volumes and densities of patents.

The second paper by Anthony Kimpton looks at urban mobility and examines rail heading behaviours at park and ride facilities for the car dependent city of Brisbane, Australia. Using data derived from anonymised licence plate surveys of park and ride facilities, results from regression models reveal that commuters tend to maximise their travel within private vehicles tending to travel beyond the nearest facility to those located closer to the inner city.

In a study of extreme weather and coastal vulnerability in Santa Barbara, California, Alan Murray and colleagues adopt a spatial analytic approach to reveal the geographic variation in risk of flooding, flash floods, mudslides and debris flows. They highlight the importance and role of high-resolution spatial data embedded within a decision support tool as critical in helping to reduce risk and enhance disaster response efforts.

Examining the visitation dynamics of third places across a large metropolitan university campus Rosabella Borsellino and colleagues showcase a suite of metrics to reveal similarities and differences over space and time. Using Wi-Fi data their findings reveal interesting differences within types of places that are functionally the same but are associated with dissimilar visitation dynamics, pointing to the importance of localised individual behaviours alongside the role played by the broader spatial context.

The next paper by William James and colleagues focusses on the use of geodemographics to understand the patterns and trends of meat expenditure and consumption in the United Kingdom. Looking over a 9 year period to 2017 and employing spatial microsimulation to derive expenditure estimates for 380 areas across the country, findings reveal interesting trends, patterns and fluctuations in meat expenditure and how these vary by geodemographic group.

The final paper by Sisi Wang and colleagues draws on a primary WeChat administered survey (a mobile social media application commonly used by the Chinese population) to examine settlement pathways and residential migration patterns of 
mainland-China born migrants in Australia. Employing regression modelling they reveal three key dimensions that drive residential moves (1) individual migrant characteristics (particularly English proficiency); (2) education/career and residential environment; and, (3) the desire to co-locate with friends and family, or improve proximity to work and transport options.

Taken together this special issue has sought to draw together a set of studies that highlight the breadth and diversity of contemporary spatially integrated social science. This diversity is evident in terms of the research questions under investigation, but also in the range of data used, methods applied to answering those questions and the geographical focus of the case studies.

In sum, the aim of this special issue is to offer a new point of reference by showcasing a suite of contemporary applications in spatially integrated social science. Finally, we would like express our sincere thanks to each of the contributing authors, the referees and the editorial team at Applied Spatial Analysis and Policy.

\section{References}

Anselin, L. (1999). The future of spatial analysis in the social sciences. Geographic Information Sciences, 5(2), 67-76.

Applied Geography Commission (2021). Applied Geography Commission. https://agcigu.wordpress. com/. Accessed 23 Jan 2021.

Goodchild, M. F., Anselin, L., Appelbaum, R. P., \& Harthorn, B. H. (2000). Toward spatially integrated social science. International Regional Science Review, 23(2), 139-159.

Goodchild, M. F., \& Janelle, D. G. (Eds.). (2004). Spatially integrated social science. Oxford University Press.

Phlipponneau M. (2004). Historical foundations of applied geography. In A. Bailly, A.J. Gibson (eds.), Applied Geography. A World Perspective. Springer pp 47-67.

Stimson, R. J. (2014). A spatially integrated approach to social science research. In Handbook of research methods and applications in spatially integrated social science. Edward Elgar Publishing.

Publisher's Note Springer Nature remains neutral with regard to jurisdictional claims in published maps and institutional affiliations. 